\title{
Estimating Synaphobranchus kaupii densities: Contribution of fish behaviour to differences between bait experiments and visual strip transects
}

\author{
Verena M. Trenkel ${ }^{a,{ }^{*}}$ and Pascal Lorance ${ }^{a}$
}

a Ifremer, rue de l'lle d'Yeu, BP 21105, 44311 Nantes cedex 3, France

* Corresponding author : V. M. Trenkel, Tel.: +33 240374157; fax: +33 240374075, email address : verena.trenkel@ifremer.fr

\begin{abstract}
:
Kaup's arrowtooth eel Synaphobranchus kaupii is a small-bodied fish and an abundant inhabitant of the European continental slope. To estimate its local density video information using the remotely operated vehicle (ROV) Victor 6000 were collected at three locations in the Bay of Biscay slope. Two methods for estimating local densities were tested: strip transect counts and bait experiments. For bait experiments three behaviour types were observed in about equal proportions for individuals arriving near the seafloor: moving up the current towards the ROV, moving across the current and drifting with the current. Visible attraction towards the bait was the highest for individuals swimming against the current $(80 \%)$ and about equally low for the other two types (around 30\%); it did not depend on current speed nor temperature. Three main innovations were introduced for estimating population densities from bait experiments: (i) inclusion of an additional behaviour categorythat of passively drifting individuals, (ii) inclusion of reaction behaviour for actively swimming individuals and (iii) a hierarchical Bayesian estimation framework. The results indicated that about half of individuals were foraging actively of which less than one third reacted on encountering the bait plume and the other half were drifting with the current. Taking account of drifting individuals and the reaction probability made density estimates from bait experiments and strip transects more similar.
\end{abstract}

\section{Research highlights}

Inclusion of passively drifting individuals. Inclusion of reaction behaviour for actively swimming individuals. A hierarchical Bayesian estimation framework.

Keywords: Bayesian; Hierarchical model; Natural and reaction behaviour; Video; Deep-water 


\section{Introduction}

The use of baited cameras for studying deep-ocean species richness, species abundance and biomass and individual behaviour has a long history (Bailey et al., 2007). The popularity of this methods stems from its ease of use and low cost of deployment. The main disadvantages for population density estimation are selective observation of scavengers only and the large number of assumptions required for the estimation, regarding diffusion of the odour plume, foraging strategy of individuals and swimming speeds (Bailey et al., 2007). In contrast, strip transects using towed cameras, remotely operated vehicles (ROV) or manned submersibles offer a more direct, but often more expensive way of estimating species densities, provided care is taken to calibrate the observation field (Trenkel et al., 2004). However, reactions to the ROV can also bias strip transect estimates (Stoner et al., 2008; Trenkel et al., 2004).

Traditionally for estimating local fish densities from baited camera experiments the time of first arrival together with a model on odour plume spreading has been used (Sainte-Marie and Hargrave, 1987). More recently, Farnsworth et al. (2007) proposed a revised model which makes use of the number of fish present at the bait at different times during the initial phase, thus providing increased precision of density estimates due to the use of more information than just the first arrival. Farnsworth et al. proposed estimators for two foraging behaviours: directionally persistent cross-current foraging and cross-current foraging with random reorientation. Alternative foraging strategies are sit and wait or passive drifting, though both might also be interpreted as resting not foraging. Different density estimates are obtained depending on which foraging strategy is assumed in the model, with cross-current foraging leading to the expected fastest arrival at baits and the largest numbers (Bailey and Priede, 2002). To make models tractable a single foraging strategy is generally assumed. In situ visual observations have shown that while this is a reasonable assumption for some species, others might use several foraging strategies (Lorance and Trenkel, 2006; Uiblein et al., 2003).

Behavioural responses to the bait or observation platform in addition to foraging type determine the number of individuals expected to be seen. Jamieson et al. (2006) found that $36 \%$ of Coryphaenoides armatus individuals never entered the field of view of the central camera which would normally serve to estimate population density. Farnsworth et al. (2007) using a hidden Markov model estimated that about two thirds of individuals of the same species present at baited lander experiments were never seen by the camera. Reaction behaviour on encounter of the bait plume, which can be either to turn and swim up the bait plume or continue as before, is another determining factor for cross-current foraging individuals or those with a sit and wait strategy. The foremost factor affecting reaction probabilities is probably the bait type and thus species specific. Further, indirect evidence from observed close up reactions to an ROV and a submersible suggest that the proportion of individuals reacting might depend on environmental conditions (Lorance and Trenkel, 2006; Uiblein et al., 2002).

The variance of the arrival times and thus the number of individuals observed in a given time interval by repeated bait experiments will depend on the spatial distribution with habitat preferences becoming predominant at larger scales. For short bait experiments which are attracting individuals from a small area it seems appropriate to assume a random spatial distribution of individuals leading to the number of arrivals being described by a Poisson distribution. 
The Kaup's arrowtooth eel Synaphobranchus kaupii is a small-bodied fish, abundant inhabitant of the European continental slope (Gordon and Mauchline, 1996). In this study density estimates derived from bait experiments carried out with the ROV Victor 6000 and visual strip transect counts (described in Trenkel et al. 2004b) for three locations on the Bay of Biscay continental slope (1100 to $1500 \mathrm{~m}$ ) are compared. Population density estimators for bait experiments are generally deterministic, with the exception of the stochastic model proposed by Farnsworth et al. (2007). Here we treat model parameters as random variables and use a hierarchical Bayesian approach. The Bayesian approach has several advantages in the context of density estimation from bait experiments. First it allows to include behaviour information derived from other studies and experiments in prior distributions. Second, it provides the joint posterior distribution for all model parameters which permits to investigate the relationship between parameters. Parameters considered to be confounded in the maximum likelihood context exhibit joint posterior distributions with strong correlation patterns. In the extreme case of extrinsic parameter redundancy, all model parameters are not identifiable with the data set at hand which prevents parameter estimation by maximum likelihood (Gimenez et al., 2004) but not in a Bayesian context. Small data sets are common for bait experiments which increases the possibility of extrinsic parameter redundancy. Third, no normality assumption needs to be made for obtaining confidence intervals as the full marginal posterior distribution is available for all parameters. Hierarchical Bayesian models have been used for density estimation for terrestrial camera-trap studies using markrecapture methodology (Royle et al., 2009) but not for bait experiments to the best of our knowledge.

In the following we will first describe the experimental set up, the behavioural data analysis and the hierarchical Bayesian model used for estimating local densities that includes variables for foraging strategy and reaction response. We then report on natural and behavioural responses to the baits and compare bait data derived density estimates to visual strip transect estimates.

\section{Material and Methods}

\subsection{Data collection}

Three study sites located on the continental slope of the Bay of Biscay were sampled during the VITAL cruise in late August and early September 2002 using the ROV Victor 6000. The first site, the Meriadzek Terrace, is characterised by soft sediments and has been commercially exploited in the past. The second site, the terrace located between the canyon of Belle Île and the canyon of St Nazaire (referred to as St Nazaire Terrace in this paper) is similar to the first but has hardly been exploited by commercial trawlers, probably partly due to its small size. The third site, the Belle Île Canyon, is located adjacent to this terrace; it is a mixture of steep cliffs and soft sediment slopes. The depth range $1100-1500 \mathrm{~m}$ was investigated in all sites by perpendicular strip transects starting from the deepest point and moving up slope (see full description in Trenkel et al 2004b). Bait experiments were carried out at all sites at regular intervals (every 12 hours) along the transects (Figure 1).

Two types of bait were used, a standardised paste and cod fillets (only on St Nazaire Terrace, Table 1). The paste was made of fish farming food pellets mixed with sea water (480 $\mathrm{g}$ per liter). Sardine oil was added $\left(3 \mathrm{~cm}^{3}\right.$ per liter) to increase the smell of the bait. The bait was filled into identical bottles ( $\sim \mathrm{cm}$ diameter opening, $15.5 \mathrm{~cm}$ high). At the beginning of the experiment the ROV opened the bottle, put it onto the ground and retreated a few meters perpendicular to the current to observe fish arrival. After it was judged that no more individuals were going to arrive, the ROV shook the bottle to create a new plume and continued observations. In one experiment the bottle was shaken a second time. 
Video tapes were analysed in the laboratory after the cruise. For each individual arriving, the time and direction of arrival, the initial behaviour and the reaction to the bait were noted. Initial behaviour was categorised by the position in the water column: near the seafloor $(<1$ body length) or higher up (>1 body length) and the locomotion type: drifting or moving with current, swimming against current or swimming perpendicular to the current. Reaction to the bait was categorised as not interested, attracted, touching bait bottle or eating bait. The latter three categories were summarised as "interested in bait" for certain analyses. When possible the speed of the first individual arriving swimming against the current was estimated. Using the size of the bait bottle as a yard stick the time taken for swimming a certain distance $(1 \mathrm{~cm}$ on the video screen) was recorded on two occasions and used to calculate the average arrival speed.

At the deepest point sampled at each site (1460-1550m), an autonomous lander equipped with a current meter, a temperature probe, a turbidity meter and a bait system (including a rotating bait dispenser with the same bait bottles as used by the ROV and a camera) was deployed for three days. Data from these sensors were recorded every minute to every two minutes. The bait bottle was automatically opened for 4 hours and subsequently closed 12 hours before the next experiment. A temperature probe was also carried by the ROV. In this study current speed and direction from the lander and temperature from the ROV were used. The results from the autonomous bait system were not exploitable as instead of dispersing after each bait experiment, individuals tended to stay around. This might have been due to the build up of a food chain with the bait attracting amphipods which in turn attracted fish. Alternatively it could also have been that the structure generated aggregations, with fish exploring the lander being seen on the photos independent of whether a bait experiment was running or not.

\subsection{Behaviour analysis}

Generalized additive models (GAM) were used for analysing reaction behaviour to the bait and duration of stay as a function of environmental covariates (water temperature, current speed, depth), bait type (aquaculture paste or cod fillet) and initial locomotion type. As depth and temperature were strongly negatively correlated $(p<0.001)$, only temperature was used as it is expected to affect behaviour directly.

The probability of an individual showing interest in the bait was modelled by the logistic regression

$\mathrm{P}($ interested $)=$ Bait type + Locomotion $+\mathrm{s}($ Current speed $)+\mathrm{s}($ Temperature $)$

A thin plate regression spline denoted as $\mathrm{s}($ ) was used for modelling temperature and current to allow for a non linear relationship (Wood, 2003). The same logistic model was used for investigating the probability of an individual actually eating the bait

$P($ eating bait $)=$ Bait type + Locomotion $+s($ Current speed $)+s($ Temperature $)$

The duration an individual stayed around the bait was modelled by a Gaussian distribution and included bait type, reaction, current speed and temperature as explanatory variables

Duration $=$ Bait type + Reaction $+s($ Current speed $)+s($ Temperature $)$ 
For swimming individuals, the velocity of the first arriving individual was modelled as a function of current speed and temperature (a non-linear model could not be fitted for one variable due to the small number of observations) using a Gamma distribution

Swimming velocity $=$ Site + Current speed $+s($ Temperature $)$

All models were fitted using the package mgcv in R estimating optimal smoothing parameters for the thin plate splines using maximum likelihood (Wood, 2006). Residual plots were used to check modelling assumptions.

\subsection{Density estimation}

\subsubsection{Bait experiments}

The number of fish having arrived at the bait at time $T$ depends on local fish density, plume spreading, individual foraging strategy and reaction behaviour on encountering the bait plume. Although a substantial proportion of $S$. kaupii have been observed to remain stationary (Uiblein et al., 2002), only active and drifting individuals are observable in bait experiments. Therefore we assumed that individuals used only one of two foraging strategies: active cross-current foraging or passive drifting. All individuals arriving at the bait actively swimming against or across the current were assumed to have been cross-current foraging. Individuals arriving at the bait drifting were assumed to have been drifting since the beginning of the experiments. In other words, it is assumed that individuals did not change the foraging strategy during the duration of the experiments (max. 20 mins).

Following Farnsworth et al. (2007), the number of actively swimming individuals $n_{i j}(T)$ having arrived at time $\mathrm{T}$ after the beginning of experiment $\mathrm{j}$ at site $\mathrm{i}$ is

$$
\begin{aligned}
& E\left[n_{i j}(T)\right]=\left(1-P_{\text {drift }}\right) P_{\text {react }} \frac{u_{i j} v_{i} T}{2\left(u_{i j}+v_{i}\right)} w_{i} T \delta_{i j}=A\left(1-P_{\text {drift }}\right) P_{\text {react }} \delta_{i j} \\
& \mathrm{n}_{\mathrm{ij}}(\mathrm{T}) \sim \operatorname{Poisson}\left(\mathrm{E}\left[\mathrm{n}_{\mathrm{ij}}(\mathrm{T})\right]\right)
\end{aligned}
$$

with E[ the expected value, $u_{\mathrm{ij}}$ current speed, $v_{i}$ foraging speed and $w_{i}$ plume following speed. The local $S$. kaupii density is $\delta_{\mathrm{ij}}$ and the proportion of individuals drifting $\mathrm{P}_{\text {drift. }}$ Among the individuals that foraged actively, on encounter of the bait plume a proportion $P_{\text {react }}$ turned into the current and swam up to the bait. The underlying hypothesis of the Poisson distribution is that individuals are randomly distributed in space. For this model the area $A_{1}$ in which the observed animals were at the beginning of the experiment has a triangular shape (see Figure 2). Its size depends on current speed, foraging speed, plume following speed and the duration of the experiment.

For drifting individuals it is assumed that all observed animals came from a strip of width $s$ whose length depends on the time of arrival $T$; the area observed is $A_{2}$ (Figure 2). The model for the number of individuals arrived drifting at time $T m_{i j}(T)$ is then

$$
\begin{aligned}
& E\left[m_{i j}(T)\right]=P_{\text {drift }} u_{i j} S T \delta_{i j}=A_{2} P_{\text {drift }} \delta_{i j} \\
& m_{i j}(T) \sim \text { Poisson }\left(E\left[m_{i j}(T)\right]\right)
\end{aligned}
$$


Local S. kaupii densities $\delta_{\mathrm{ij}}$, i.e. for a given experiment, were modelled by a normal distribution with site specific mean population density $\lambda_{i}$ and a common overall dispersion parameter $\mathrm{T}$

$$
\delta_{\mathrm{ij}} \sim N\left(\lambda_{\mathrm{i}}, \mathrm{T}\right)
$$

The input data were counts and corresponding arrival times by category, $n_{i j}(T)$ and $m_{i j}(T)$ (Table 1), and current speeds $u_{i j}$ measured by the lander. An average fish foraging speed $v_{i}$ for all sites of $5.4 \mathrm{~cm} \mathrm{~s}^{-1}$ was estimated by combining the published $S$. kaupii swimming speed of 0.2 body lengths per $s$ found by Uiblein et al. (2002) with a mean body size of 27 $\mathrm{cm}$ measured during the same study just after the bait experiments (Rochet et al., 2006). For the plume following speed at each site $w_{i}$ the average speed of the first arriving individuals was used. The strip width $s$ in which all drifting individuals were seen was somewhat arbitrarily assumed to be $3 \mathrm{~m}$. Model parameters and fixed values are summarised in table 2 .

Model parameters were estimated with a hierarchical Bayesian model. The prior for mean site densities $\lambda_{\mathrm{i}}$ was an exponential distribution with hyperparameter $\zeta$ which in turn had an uninformative (conjugate) gamma distribution as prior (Table 2). $P_{\text {drift }}$ and $\mathrm{T}$ had uninformative prior distributions (Table 2). For $\mathrm{P}_{\text {react }}$ an informative Beta distribution (conjugate prior) with a mode at 0.3 was selected based on the observed reactions of individuals near the bait (see section 3.1). For comparison, a model run with an uninformative prior for $P_{\text {react }}$ was carried out.

Bayesian model estimation was carried out by Monte Carlo Markov Chain (MCMC) using OpenBUGS 3.12 (Spiegelhalter et al., 2010) from R via the R2WinBUGS package (Sturtz et al., 2005). The required number of samples and burn-in period was estimated from a pilot run using the method proposed by Raftery and Lewis (1995) which is implemented in the Coda package in R. For the final estimates three chains with a burn-in period of 150000 were run; the chains were thinned by taking every 450th sample retaining overall 1000 samples.

Density estimates were carried out using only the data from standardised bait experiments (aquaculture paste), before shaking the bottle, and up to 20 minutes after starting the experiment.

\subsubsection{Visual strip transects}

The method used for obtaining density estimates from visual strip transect counts is fully described in Trenkel et al. (2004). The estimation consists in dividing the number of individuals encountered in a strip by the area observed (A3 in Figure 2).

\section{Results}

\subsection{Behaviour}

Across all sites and experiments, only 12 out of 251 individuals were seen higher up in the water column, and two thirds of them were drifting with the current (Figure 3a). In contrast, among individuals arriving close to the sea bottom, about one third was drifting with the current, one third swimming perpendicular to the current and one third swimming against the 
current. The reaction to the bait clearly depended on the locomotion type. Most individuals (80\%) swimming against the current were interested in the bait, among which $30 \%$ touched it and $16 \%$ ate the aquaculture bait (Figure 3b); cod fillets were touched by $10 \%$ and eaten by $62 \%$ (Figure 3c). Between 60 and $80 \%$ of individuals swimming perpendicular to the current or drifting were not interested in the bait, independent of the bait type.

The GAM model (eq. 1) confirmed that the initial locomotion type significantly affected the probability of an individual being interested in the bait $(p<0.001)$, while neither current speed nor temperature had any explanatory power $(p>0.05)$. Bait type did not play a role for the probability of being interested $(p>0.05)$. The final model for the probability of being interested with only initial locomotion type explained $15.6 \%$ of deviance. In contrast, the probability of eating (eq. 2) depended on bait type $(p<0.001)$ with more individuals eating the cod bait as well as initial locomotion type $(p<0.001)$; again, neither current speed nor temperature were significant $(p>0.05)$. The final model with only bait and locomotion type explained $30.1 \%$ of deviance.

The duration an individual stayed around the bait depended on its reaction behaviour and the bait type (Figure $4 a \& b$ ). Individuals eating the aquaculture paste in the bottles stayed the longest (median duration $150 \mathrm{~s}$ ). The model for staying duration (eq. 3) confirmed the importance of bait and reaction type $(p<0.001)$ while current speed was just significant $(p=0.045)$ and temperature did not have any explanatory power $(p>0.05)$. Staying duration decreased with increasing current speed (Figure 4c). The final model with bait and reaction type and current speed explained $33.7 \%$ of deviance.

The swimming velocity of the first arriving individual did not depend on current speed nor temperature $(p>0.05)$ but differed significantly between study sites $(p=0.026)$; the model with site explained $50.6 \%$ of deviance.

\subsection{Density estimates}

The cumulative number of individuals in all experiments was much lower at Meriadzek Terrace than at the other two sites (Figure 5a). The arrival time of the first swimming or drifting individual showed a linear relationship with current speed for Belle lle canyon and to some degree for St Nazaire Terrace (Figure $5 b$ \& c). At Meriadzek Terrace current speed did not seem to affect arrival time. This might indicate a violation of the assumption that higher current speeds would lead to faster arrival times.

Density estimates with the Bayesian hierarchical model as well as from strip transects showed differences between sites (Table 3). The lowest density was found on Meriadzek Terrace with both methods. In contrast the strip transect based mean density estimates was highest for St Nazaire Terrace while the Bayesian median posterior estimate was highest for Belle île canyon. Strip transect based estimates were higher for all sites by a factor of 2 to 3.6. Assuming an uninformative prior for the proportion of individuals to react to the bait plume in the Bayesian analysis led to slightly lower density estimates for all sites but did not change the ordering of sites (see Appendix).

Inspection of contour plots of pairwise joint posterior distributions confirmed that the mean density estimates for the three sites were independent of each other and of the two behaviour parameters, i.e. the joint posteriors showed no correlations, with the exception of 
the mean density for Belle île canyon whose joint posterior with $P_{\text {react }}$ was decreasing concave (not shown). The shapes of the pairwise joint posteriors were similar in the case of an uninformative prior for $\mathrm{P}_{\text {react }}$.

The marginal posterior distribution for the proportion of drifting individuals, $\mathrm{P}_{\text {drift, }}$ was slightly asymmetrical with a left hand shoulder, a median of 0.54 and a mode around 0.6 (Figure 6a). The marginal posterior distribution for the proportion of individuals reacting, $P_{\text {react }}$, was nearly identical to the prior with median 0.27 (Figure $6 \mathrm{~b}$ ) which indicates that the data contained little information on this parameter. However, when using an uninformative prior for this parameter the posterior was clearly different from the prior (see Appendix). The joint posterior distribution for $P_{\text {drift }}$ and $P_{\text {react }}$ showed a narrow rising concave shape (Figure 6c). Thus the two parameters were positively related and in this case considering only marginal distributions can be misleading. Indeed, though the marginal posterior distribution for $\mathrm{P}_{\text {drift }}$ was sensitive to the prior distribution used for $\mathrm{P}_{\text {react }}$ their joint posterior distribution was less sensitive (see Appendix).

\section{Discussion}

Three main innovations were introduced for estimating population densities from bait experiments and demonstrated for S. kaupii: i) inclusion of an additional animal category that of individuals passively drifting with the current, ii) inclusion of reaction behaviour for actively swimming individuals and iii) a hierarchical Bayesian estimation framework.

Given that not all individuals were actively foraging, ignoring drifting individuals would have halved the number of observations available for density estimation (Table 1). Therefore the model by Farnworth et al. (2007) was extended by adding an independent equation for the proportion of individuals drifting with the current (eq. 6). Further, it was assumed that not all individuals that were foraging actively at the time of the bait experiment, turned and swam up to the bait. Inclusion of this reaction behaviour was deemed necessary based on the reported variations in the probability of an individual showing interest in the bait (section 3.1). Environmental conditions, at least temperature and current speed did not seem to be important to explain these differences and hence these variables were not included in the model. It should be noted that the proportion of individuals reacting could only be estimated because the number of individuals drifting with the current were included in the estimation.

The results showed that about half of individuals were drifting and half were actively foraging. Only the individuals among the later group were susceptible to react downstream encounter of the bait plume and as the estimate for the proportion reacting showed, only less than one third did so. Thus, had we only considered swimming individuals and assumed that all individuals present at the time in area $A 1$ in figure 2 had reacted, population density estimates would have been about 8 times lower. The fact that not all individuals reacted corroborates the findings by Priede and Merrett (1998) of a non-linear relationship between trawl based density estimates and numbers attracted to baits of the deep-water grenadier Coryphaenoides armatus. Here it was assumed that the proportion reacting depended only on the foraging strategy, but it might well depend also on other factors such as local density.

A hierarchical Bayesian approach was used and samples from the joint posterior distribution were obtained by MCMC. The two behaviour parameters $P_{\text {drift }}$ and $P_{\text {react }}$ were positively correlated as could be seen from their joint posterior distribution (Figure 6c). Correlations between parameters delay convergence of the MCMC chains. To overcome the problem of slow convergence it was necessary to have a very long burn-in period and discard many samples. Despite these precautions complete convergence cannot be guaranteed. Further, 
the data contained little information on $P_{\text {react }}$ which can be seen from the fact that the posterior was rather wide in the case of an uninformative prior (Appendix). In this situation it is recommendable to use an informative prior for $P_{\text {react }}$ or alternatively $P_{\text {drift }}$ or both if available.

When comparing population densities derived from strip transects and bait experiments, estimates from strip transect counts were always higher by a factor of 2 to 3.6. Part of this difference is accounted for by the $10-40 \%$ of inactive individuals (Uiblein et al., 2002) that were not observable here. Further, for two parameters in the model no local data were available and their values had to be fixed: foraging speed and strip width (Table 2). Foraging speed was based on swimming speed measurements from the literature combined with mean body length measurements from the study sites. However, we ignored that swimming speed varies with body size, but also temperature and possibly depth (Uiblein et al., 2002). The value for strip width was an educated guess. Reducing the strip width in which drifting animals were counted from 3 to $2 \mathrm{~m}$, reduced the ratios between the two methods to 1.6 2.8. Finally, the information for both methods was based on videos collected with an ROV using artificial light and introducing noise and chemical stimulii. Reviewing the literature and anecdotal observations, Stoner et al. (2008) concluded that many species react to underwater vehicles at certain times. During the study reported here, experimental strip transects were carried out under two light levels and at two survey speeds. The results showed that $S$ kaupii is likely to have been attracted to the ROV (Trenkel et al., 2004). This attraction should have affected both strip transect counts and bait experiments though it is difficult to say whether the induced upward bias in density estimates was the same for both methods. If it was not, it might also provide an explanation for the observed difference in density estimates. Finally, the difference between the two sets of density estimates was largest for the two terraces. A possible explanation is that near bottom currents clearly followed the tidal cycle on the terraces and were more disturbed in the canyon (Lorance and Trenkel, 2006) thus inducing more plume dispersion and better detection in the canyon.

The type of bait is important for which species are attracted and how they react. Most published studies have used fish bait, e.g. Priede and Merrett (1998). In this study a standardised bait made from aquaculture pellets was used for most experiments. It attracted primarily S. kaupii, though other species such as Lepidion eques, Bathypterois dubius and Nezumia aequalis were also attracted on occasion but not in high enough numbers to allow density estimation. This demonstrates the importance of the choice of bait but probably also the concentration of the bait plume. S. kaupii is the most abundant fish species in the study site. The few experiments carried out using cod bait showed that $S$ kaupii reacted differently and stresses the need for using standardised bait (Figure 3).

In conclusion, including drifting animals and reaction behaviour turned out to be important for estimating population densities for $S$. kaupii. The presented model complements the behaviour model presented by Farnsworth et al. (2007) by including individuals drifting with the current and a parameter for the proportion of reacting individuals. Finally, the hierarchical Bayesian framework allowed parameter estimation in the context of limited data.

\section{Acknowledgement}

We are grateful to our colleagues, the pilots of Victor 6000 and the crew of RV L'Atalante for assisting in the data collection at sea and the video exploitation for strip transects. We thank Gildwen Morain for analysing the videos sequences of bait experiments. 


\section{References}

Bailey, D.M., King, N.J., Priede, I.G., 2007. Cameras and carcasses: historical and current methods for using artificial food falls to study deep-water animals. Marine Ecology Progress Series 350, 179-191.

Bailey, D.M., Priede, I.G., 2002. Predicting fish behaviour in response to abyssal food falls. Marine Biology 141, 831-840.

Farnsworth, K.D., Thygesen, U.H., Ditlevsen, S., King, N.J., 2007. How to estimate scavenger fish abundance using baited camera data Marine Ecology Progress Series 350, 223-234.

Gimenez, O., Viallefont, A., Catchpole, E.A., Choquet, R., Morgan, B.J.T., 2004. Methods for investigating parameter redundancy. Animal Biodiversity and Conservation 27.1, 1-12.

Gordon, J.D.M., Mauchline, J., 1996. The distribution and diet of the dominant, slopedwelling eel, Synaphobranchus kaupi, of the Rockall Trough. Journal of the Marine Biological Association U.K. 76, 493-503.

Jamieson, A.J., Bailey, D.M., Wagner, H.-J., Bagley, P.M., Priede, I.G., 2006. Behavioural responses to structures on the seafloor by the deep-sea fish Coryphaenoides armatus: Implications for the use of baited landers. Deep-Sea Research I 53, 1157-1166.

Lorance, P., Trenkel, V.M., 2006. Variability in natural behaviour, and observed reactions to an ROV, by mid-slope fish species. Journal of Marine Experimental Biology and Ecology 332, 106-119.

Priede, I.G., Merrett, N.R., 1998. The relationship between numbers of fish attracted to baited cameras and population density: Studies on demersal grandiers Coryphaenoides (Nematonurus) armatus in the abyssal NE Atlantic Ocean. Fisheries Research 36, 133-137.

Rochet, M.-J., Cadiou, J.F., Trenkel, V.M., 2006. Precision and accuracy of fish length measurements obtained with two visual underwater methods. Fishery Bulletin 104, 1-9.

Royle, J.A., Nichols, J.D., Karanth, K.U., Gopalaswamy, A.M., 2009. A hierarchical model for estimating density in camera-trap studies. Journal of Applied Ecology 46, 118-127.

Sainte-Marie, B., Hargrave, B.T., 1987. Estimation of scavanger abundance and distance of attraction to bait. Marine Biology 94, 431-443.

Spiegelhalter, D., Thomas, A., Best, N., Lunn, D., 2010. OpenBUGS User Manual. Version 3.0.8, March 2010.

Stoner, A.W., Ryer, C.H., Parker, S.J., Auster, P.J., Wakefield, W.W., 2008. Evaluating the role of fish behaviour in survey conducted with underwater vehicles. Canadian Journal of Fisheries and Aquatic Science 65, 1230-1243.

Sturtz, S., Ligges, U., Gelman, A., 2005. R2WinBUGS: A package for running WinBUGS from R. Journal of Statistical Software 12 (3), 1-16.

Trenkel, V.M., Lorance, P., Mahévas, S., 2004. Do visual transects provide true population density estimates for deep-water fish? ICES Journal of Marine Science 61, 1050-1056.

Uiblein, F., Lorance, P., Latrouite, D., 2002. Variation in locomotion behaviour in northern cutthroat eel (Synaphobranchus kaupi) on the Bay of Biscay continental slope. Deep-Sea Research I 49, 1689-1703.

Uiblein, F., Lorance, P., Latrouite, D., 2003. Behaviour and habitat utilization of seven demersal fish species on the Bay of Biscay continental slope, NE Atlantic. Marine Ecology Progress Series 257, 223-232.

Wood, S.N., 2003. Thin plate regression splines. Journal of the Royal Statistical Society B $65,95-114$.

Wood, S.N., 2006. Generalized additive models. An introduction with R. Chapman \& Hall/CRC, Boca Raton. 


\section{Appendix: Sensitivity to prior distribution for $\boldsymbol{P}_{\text {react }}$}

To evaluate the sensitivity of the results to the choice of the prior distribution for the proportion of individuals reacting, $P_{\text {react }}$, the model was refitted using an uninformative prior instead of the informative prior. The median density estimates were 2126 for Meriadzek Terrace, for 3247 St Nazaire Terrance and 5060 Belle île canyon. The posterior median of $P_{\text {drift }}$ was 0.7 (Figure $A 1 a$ ) and that of $P_{\text {react }} 0.4$ (Figure $A 1 b$ ). Further, the joint posterior distribution of the two behaviour parameters had a rising concave shape (Figure A1c). 
Table 1: Details for bait experiments and visual strip transects.

\begin{tabular}{|c|c|c|c|c|c|c|c|c|c|c|c|c|c|}
\hline \multirow[b]{2}{*}{ Site } & \multicolumn{9}{|c|}{ Bait experiments } & \multicolumn{4}{|c|}{ Strip transects } \\
\hline & $\begin{array}{l}\text { Paste } \\
\text { baits }\end{array}$ & $\begin{array}{l}\text { Cod } \\
\text { baits }\end{array}$ & $\begin{array}{l}\text { Duration } \\
\text { (mins) }\end{array}$ & Depth (m) & $\begin{array}{l}\text { Temp. } \\
\left({ }^{\circ} \mathrm{C}\right)\end{array}$ & $\begin{array}{l}\text { Current } \\
(\mathrm{m} / \mathrm{s})\end{array}$ & $\begin{array}{l}\text { No. } \\
\text { swimming } \\
\text { individuals }\end{array}$ & $\begin{array}{l}\text { Swimming } \\
\text { speed* }^{*} \\
(\mathrm{~cm} / \mathrm{s})\end{array}$ & $\begin{array}{l}\text { No. } \\
\text { drifting } \\
\text { individual } \\
\text { s }\end{array}$ & Start lat. & Start long. & Depth (m) & $\begin{array}{l}\text { No. } \\
\text { individuals }\end{array}$ \\
\hline $\begin{array}{l}\text { Meriadzek } \\
\text { Terrace }\end{array}$ & 6 & 0 & $6-28$ & $1142-1450$ & $5.5-7.9$ & 2.5- 14.7 & $1-3$ & $6.9-15.9$ & $1-2$ & $47^{\circ} 39^{\prime} \mathrm{N}$ & $8^{\circ} 11.4^{\prime} \mathrm{W}$ & $1092-1466$ & 1049 \\
\hline $\begin{array}{l}\text { St Nazaire } \\
\text { Terrace }\end{array}$ & 5 & 5 & $6-15$ & $\begin{array}{l}1181- \\
1506\end{array}$ & $5.9-8.9$ & $1.0-13.8$ & $1-13$ & $5.5-9.7$ & $2-13$ & $46^{\circ} 15^{\prime} \mathrm{N}$ & $4^{\circ} 42.6^{\prime} \mathrm{W}$ & $1122-1497$ & 1245 \\
\hline $\begin{array}{l}\text { Belle île } \\
\text { canyon }\end{array}$ & 7 & 0 & $6-15$ & $1164-1540$ & $5.5-8.1$ & $2.5-18.4$ & $10-25$ & $8.4-25.8$ & $2-11$ & $46^{\circ} 20.5^{\prime} \mathrm{N}$ & $4^{\circ} 41.4^{\prime} \mathrm{W}$ & $1055-1553$ & 1138 \\
\hline
\end{tabular}

${ }^{*}$ swimming speed of first individual arriving at bait 
Table 2. Model parameters, fixed values and prior distributions.

\begin{tabular}{lll}
\hline Parameter & Description & Value/prior distribution \\
\hline $\mathrm{i}$ & site index & \\
$\mathrm{j}$ & experiment index & \\
$\bar{\delta}_{\mathrm{ij}}$ & local population density (eq. 7) & $\operatorname{Exp}(\zeta)$ \\
$\lambda_{\mathrm{i}}$ & mean population density at site i (eq. 7) & dgamma $(0.01,0.01)$ \\
$\zeta$ & rate parameter of exponential distribution & dgamma(0.001, 0.001) \\
$\mathrm{T}$ & inverse standard deviation of normal distribution (eq. 7) & Beta $(2,5)$ \\
$\mathrm{P}_{\text {react }}$ & proportion of cross-current foraging individuals following bait & \\
& plume upstream (eq. 5) & Beta $(1,1)$ \\
$\mathrm{P}_{\text {drift }}$ & proportion of individuals drifting with current (eq. 5 \& eq. 6) & 3 \\
$\mathrm{~S}$ & observation strip width for drifting animals $(\mathrm{m})$ & measurements \\
$\mathrm{u}$ & current speed & 5.4 \\
$\mathrm{~V}$ & foraging speed (cm s & \\
$\mathrm{w}$ & plume following speed $\left(\mathrm{cm} \mathrm{s}^{-1}\right)$ & Meriadzek:10.6 \\
& & St Nazaire: 7.2 \\
& & Belle lle: 16.3 \\
\hline
\end{tabular}


Table 3. Density estimates (No./km²) for Synaphobranchus kaupii $\left(\lambda_{i}\right)$ using a hierachical Baysian model for bait experiment data and strip transect counts. Values are medians with 25th and 75th percentiles in brackets for the posterior distribution for Bayesian estimates and mean estimates with standard deviations in brackets for strip transects.

\begin{tabular}{llll}
\hline Method & Meriadzek Terrace & St Nazaire Terrace & Belle île canyon \\
\hline Bait experiments & $2469(1474,3533)$ & $3879(2686,9202)$ & $5867(4746,7608)$ \\
Strip transects & $8823(606)$ & $13242(850)$ & $11975(1931)$ \\
Ratio baits/transects & 3.6 & 3.4 & 2.0 \\
\hline
\end{tabular}




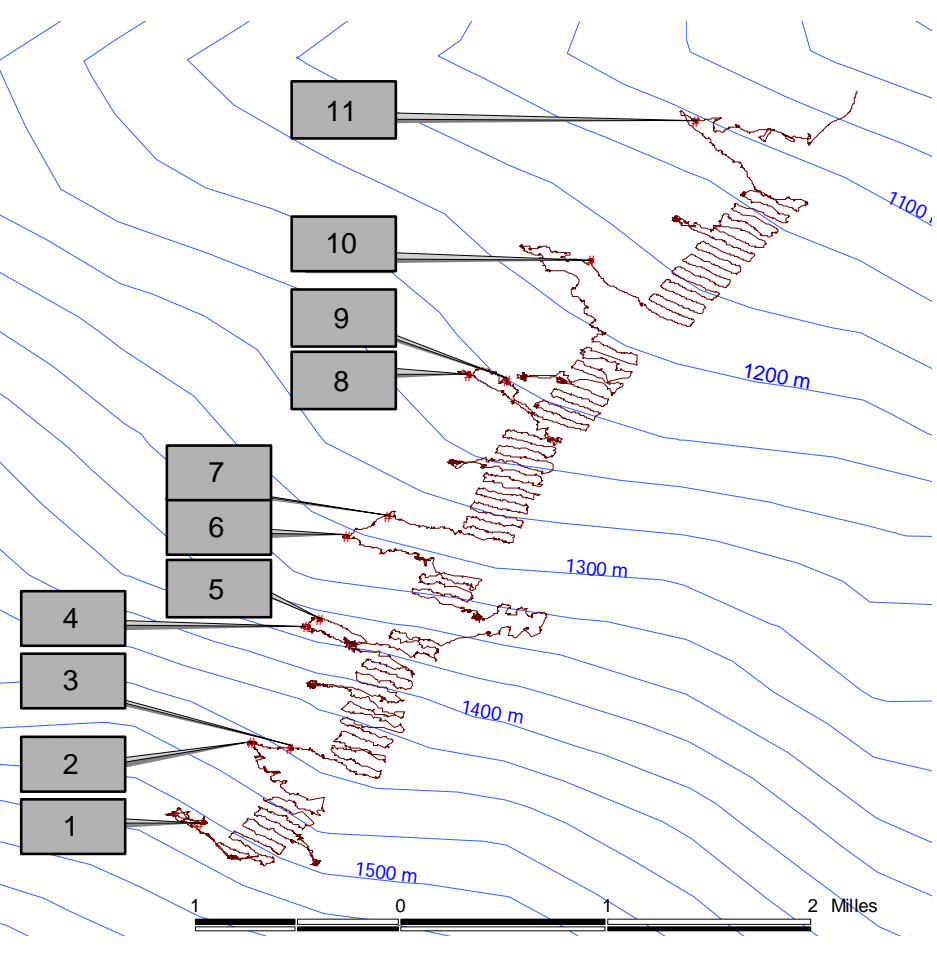

Figure 1. Survey design on Meriadzek Terrace on the Bay of Biscay continental slope (NE Atlantic). Continuous lines are ROV transects and grey boxes indicate location of bait experiments.

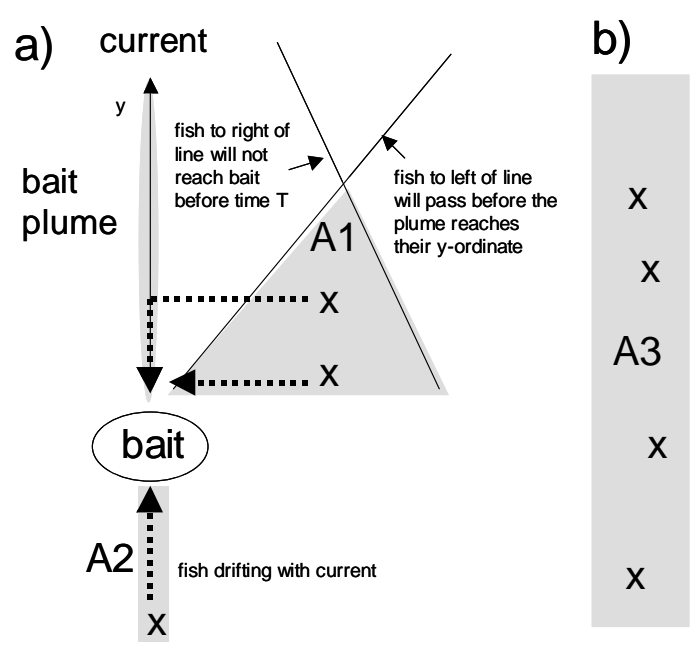

Figure 2. Surface areas for density estimation methods. a) Bait experiments, b) Visual strip transects. A1: distribution area of cross-current foraging fish observed at 
bait up to time T. A2: distribution area of drifting fish observed at bait up to time T. A3: strip transect area.

a)

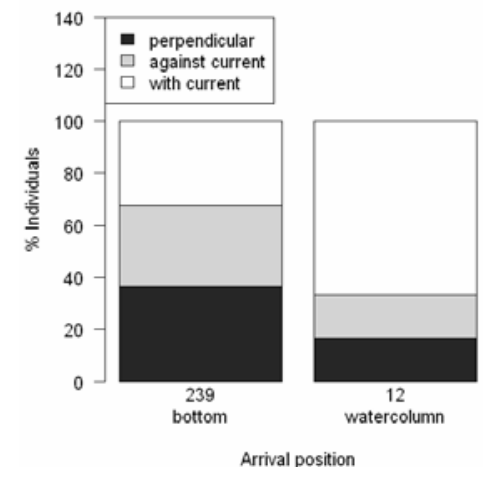

b)

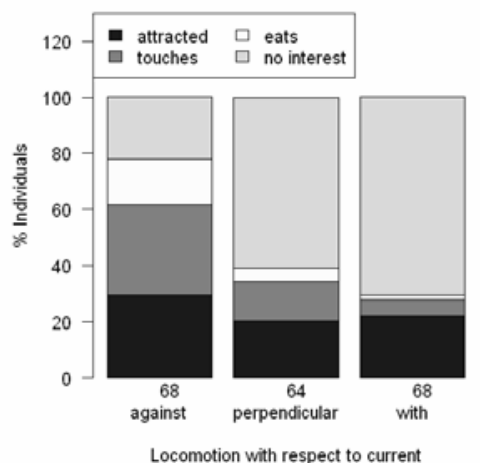

c)

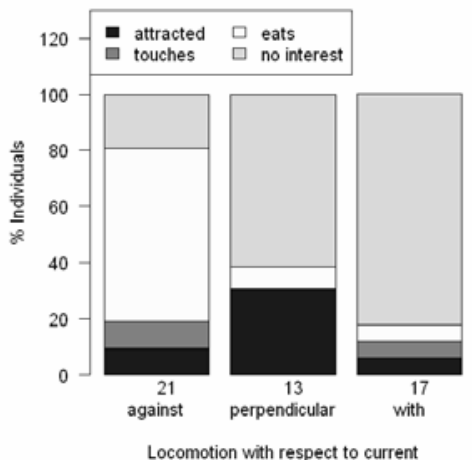

Figure 3. Behaviour observations. a) Locomotion mode for arrival positions. b) Reaction to aquaculture paste bait as a function of initial locomotion. c) Reaction to cod fillets. The number of individuals is given below each bar.
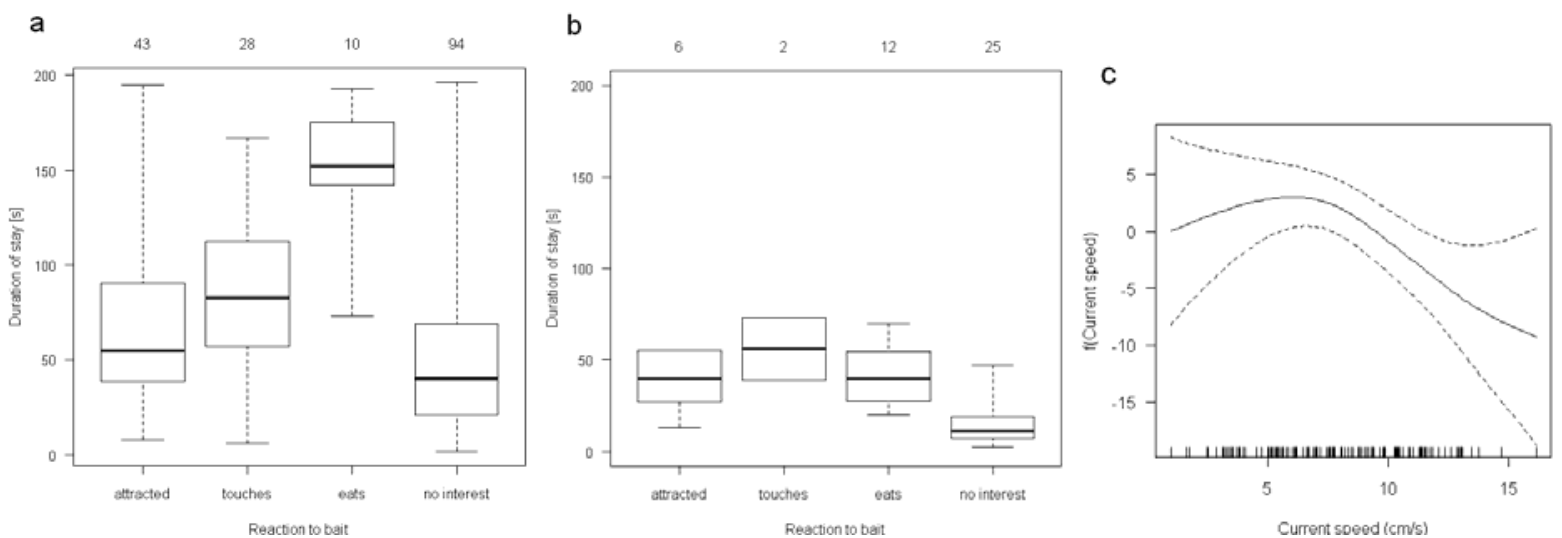

Figure 4. Duration of stay at bait as a function of reaction behaviour for bait made from a) aquaculture paste or b) cod fillets. Box encompasses 25th to 75th percentile, median bold line. Whiskers extend to min and max. Number of individuals at the top. c) Smooth function of current speed in model for duration of stay (eq 3). 
a)

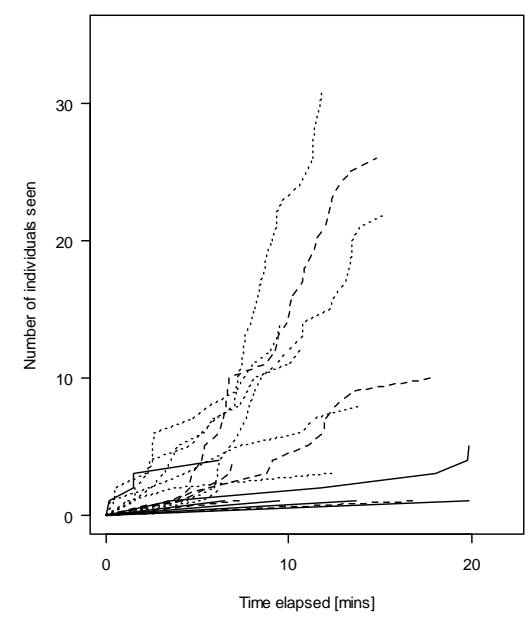

b)

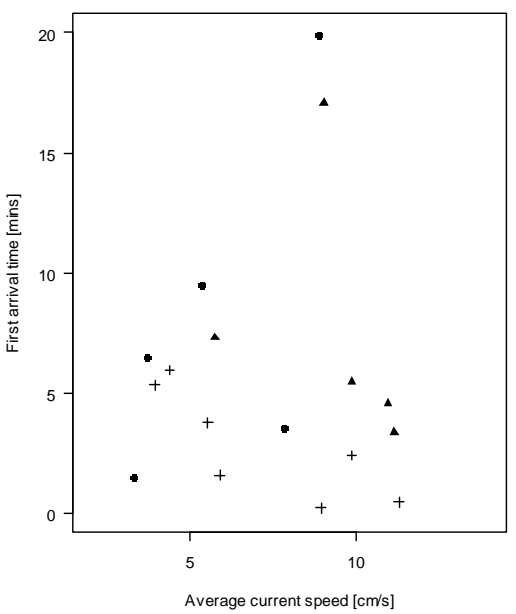

c)

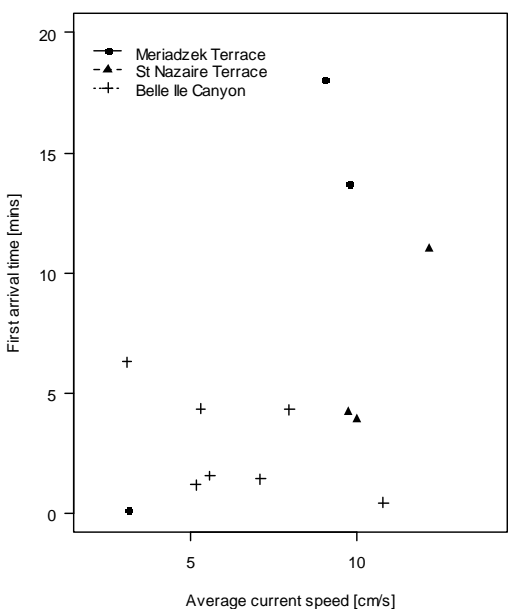

Figure 5. Cumulative number of individuals seen at bait (a) and first arrival times as a function of current speed for actively swimming individuals (b) and drifting individuals (c).
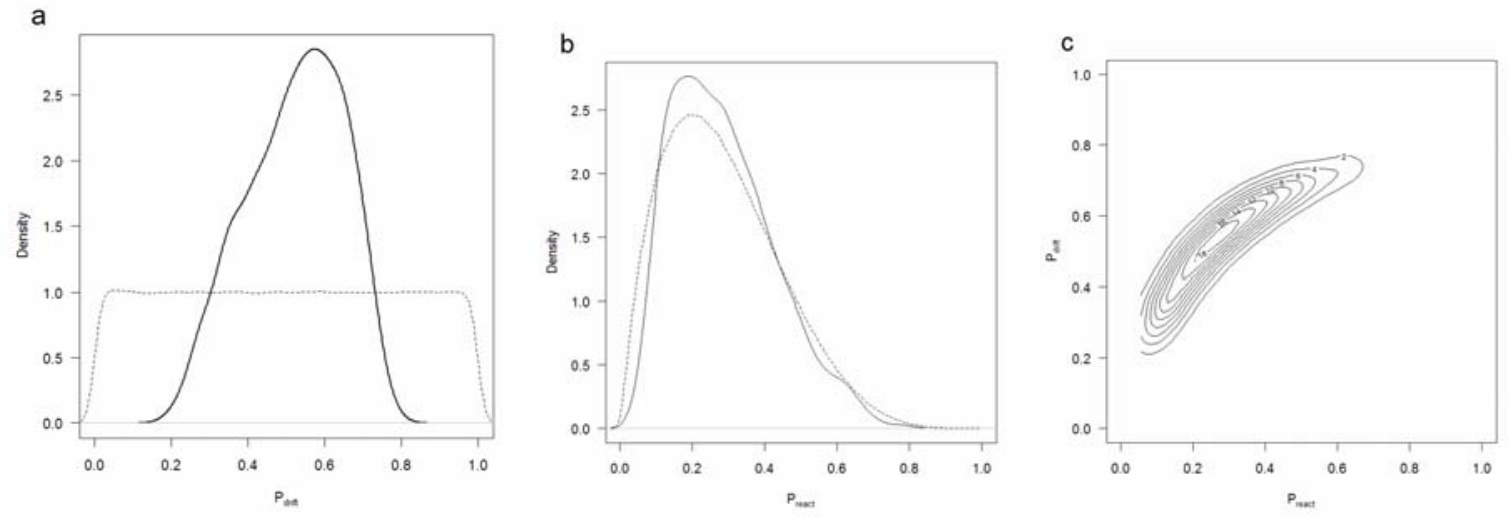

Figure 6. Bayesian hierarchical model results. Prior (dashed line) and posterior (continuous line) distributions for parameters $\mathrm{P}_{\text {react }}$ and $\mathrm{P}_{\text {dritt }}$ and their joint posterior distribution. 